\title{
Perencanaan lanskap Villa Cloud Nine Estate dengan pendekatan permakultur di Kecamatan Tegallalang, Kabupaten Gianyar, Bali
}

\author{
Atriawardhani ${ }^{1}$ I Gusti Alit Gunadi2 ${ }^{\star}$ Naniek Kohdrata1 ${ }^{1}$
}

1. Program Studi Arsitektur Pertamanan, Fakultas Pertanian, Universitas Udayana, JL. PB Sudirman, Denpasar, Indonesia

2. Program Studi Agroekoteknologi, Fakultas Pertanian, Universitas Udayana, JL. PB Sudirman, Denpasar, Indonesia

*E-mail: gunadiya@gmail.com

\begin{abstract}
Landscape Planning Villa Cloud Nine Estate with a Permaculture approach in Tegallalang District, Gianyar Regency, Bali. Villa Cloud Nine Estate is one of the tourism accommodations that cares about environmental problems in Bali. This villa has the potential for permaculture planning. A permaculture is a place that can be used for the management of agriculture and livestock to improve the quality of land, provide results and income, and remain sustainable into the future. This study aims to determine the condition of the site and its potential so as to produce a landscape plan that fits the characteristics of the villa landscape. The stages of this research are preparation, inventory, analysis, synthesis and site planning. The results of the data analysis show that the site has low land characteristics with high rainfall throughout the year. The character of the landscape on the site is natural with the main landscape elements in the form of grass and trees. The basic concept produced in this study is The Journey of Permaculture. Landscape planning is designed based on the concept of space, the concept of circulation, the concept of vegetation, and the concept of hydrology. The layout is divided to create zones that can save the time and effort needed. The vegetation is divided into production plants, conservation plants and supporting plants. Villa Cloud Nine Estate is one of the tourist accommodations that applies permaculture on the site.
\end{abstract}

Keywords: Landscape planning, Permaculture, Villa

\section{Pendahuluan}

Bali merupakan salah satu destinasi tujuan wisata dunia karena terkenal akan keindahan alamnya. Pariwisata menjadi sektor andalan dalam pembangunan di Bali. Kontribusi pariwisata terhadap perekonomian di Bali cukup tinggi. Hal ini terlihat dari kenaikan jumlah wisatawan mancanegara dan wisatawan nusantara, yakni sekitar 3.633.656 pada tahun 2000 menjadi 4.555 .739 pada tahun 2017. Kedatangan wisatawan mancanegara membawa dampak perolehan devisa sebesar 39,129 juta USD pada tahun 2017 (Suastika, 2017).

Pengembangan akomodasi pariwisata di Bali seiring waktu terus bertambah untuk memfasilitasi jumlah wisatawan yang terus meningkat. Fasilitas penunjang pariwisata tersebut berupa hotel, vila dan resort. Pertumbuhan hotel dan kamar hotel di Bali sangat pesat. Tercatat pada tahun 2006 jumlah keseluruhan hotel hanya 1.635 hotel, sedangkan pada tahun 2015 baik hotel bintang maupun non bintang mencapai 2.079 hotel. Lebih lanjut disebutkan, selain hotel jasa yang ditawarkan untuk penginapan adalah pondok wisata yang mencapai 3.150 pada tahun 2016 (Kusniarti, 2017). Berdasarkan data Badan Pusat Statistik (BPS) Kabupaten Gianyar, pada tahun 2015 luas lahan basah di Kabupaten Gianyar adalah 14.420 hekatar. Pada tahun, 2016, luas lahan basah itu berubah menjadi 14.000 hektar atau menyusut sebanyak 420 hektar (Eri, 2017). Maraknya pembangunan akomodasi wisata mengakibatkan pencemaran lingkungan dan alih fungsi lahan terjadi membuat kondisi lingkungan semakin tidak kondusif dan merusak sumber daya alam.

Pembangunan akomodasi wisata di beberapa tempat justru merusak sumber irigasi pertanian, sehingga kegiatan pertanian terganggu dan pada akhirnya mendorong berlanjutnya alih fungsi lahan. Villa Cloud Nine Estate merupakan salah satu vila yang terletak di kecamatan Tegallalang, vila ini memiliki perhatian 
terhadap masalah lingkungan dan pertanian yang ada di Bali. Upaya yang dilakukan mengurangi masalah lingkungan tersebut dengan menerapkan konsep perencanaan ekologis terhadap vila tersebut. Rencana yang dibuat akan meminimalkan penggunaan sumber daya yang tidak dapat diperbaharui, perlindungan serta perbaikan kualitas ekosistem dengan cara pembuatan permakultur.

\section{Metode}

\subsection{Lokasi dan Waktu Penelitian}

Penelitian ini berlokasi di kawasan Villa Cloud Nine Estate, Desa Keliki, Kecamatan Tegallalang, Kabupaten Gianyar, Bali. Luas area penelitian yaitu 5.911,6 $\mathrm{m}^{2}$ dan berada pada altitude $98-121 \mathrm{~m}$ dpl. Penelitian ini dilakukan dalam kurun waktu lima bulan Mei 2018 hingga Oktober 2018.

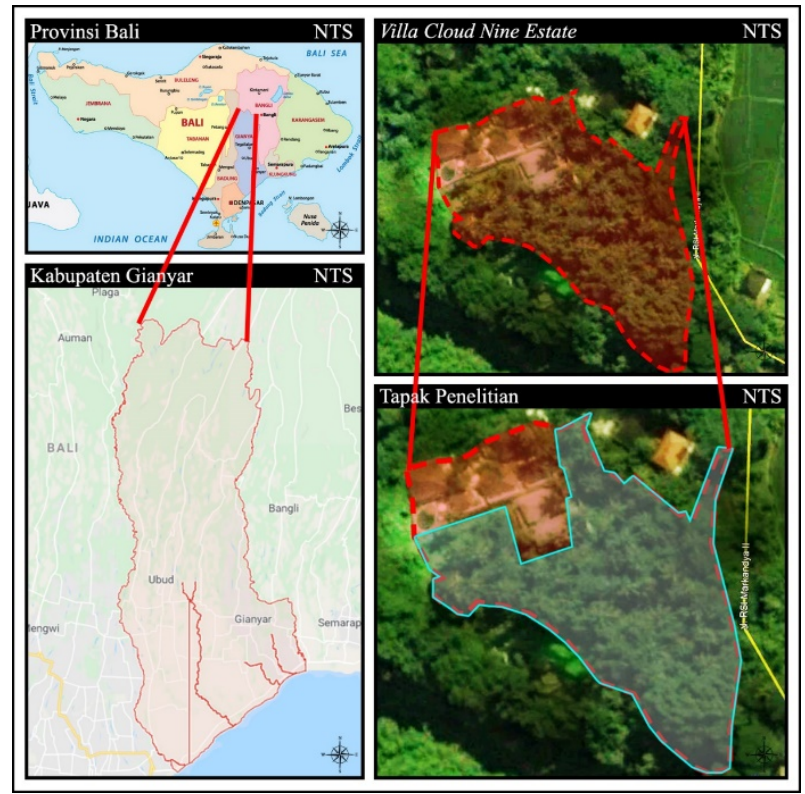

Gambar 1. Lokasi penelitian Villa Cloud Nine Estate

\subsection{Alat dan Bahan}

Alat yang digunakan dalam penelitian ini adalah alat gambar, meteran, kamera digital, laptop, perangkat lunak (Microsoft Word, Microsoft Excel, Autodesk AutoCAD, Sketch Up, dan Photoshop).

\subsection{Metode Penelitian}

Metode penelitian yang digunakan adalah metode perencanaan yang dikemukakan oleh Gold (1980). Berdasarkan metode penelitian yang dikemukakan terdapat lima tahapan utama dalam proses perencanaan yaitu tahapan persiapan, inventarisasi, analisis, sintesis dan perencanaan tapak.

\section{Hasil dan Pembahasan}

\subsection{Gambaran Umum Villa Cloud Nine Estate}

Villa Cloud Nine Estate merupakan salah satu akomodasi pariwisata yang berada di Kecamatan Tegallalang, Kabupaten Gianyar, Bali. Sebelum menjadi vila, kawasn ini merupakan lahan hitan rakyat yang dimanfaatkan oleh masyarakat untuk menanam buah lokal. Villa Cloud Nine Estate dirancang oleh arsitek Ibu Kelly Lim selaku pemilik vila bersama arsitek lanskap dari Studio Hijau Lumut (SHL Asia).

Vila ini sudah dioperasikan sejak tahun 2015. Adapun visi vila adalah "Different Ways of Luxury" yang berarti pengunjung dapat menikmati kemewahan dengan cara yang berbeda, melalui lingkungan yang dapat dilihat dari keindahan antara vila dengan alam di sekitarnya. Vila ini memiliki konsep eco-villa yaitu mengurangi pembuangan limbah plastik dan memperhatikan kualitas ekologis. Pada kesehariannya baik pengunjung maupun karyawan mengurangi penggunaan plastik, selain itu tanaman yang sedang terkena penyakit tidak menggunakan pestisida untuk mengobatinya tetapi dengan cara yang lebih alami melalui ramuan herbal. 


\subsection{Aspek biofisik lanskap}

Tapak memiliki luas total $6.842,8 \mathrm{~m}^{2}$ yang memiliki komposisi area hijau lebih dominan dengan presentasi $86,3 \%$ atau seluas $5.911,6 \mathrm{~m}^{2}$ dari luas tapak. Area terbangun berupa vila sebesar $13,6 \%$ atau seluas $931,2 \mathrm{~m}^{2}$ dari keseluruhan tapak. Tapak penelitian terletak di dataran rendah berada pada ketinggian $98 \mathrm{mdpl}$ dan $121 \mathrm{mdpl}$ dengan suhu rata- rata adalah $27,79^{\circ} \mathrm{C}$ dengan curah hujan berkisar antara $73 \mathrm{~mm}$ sampai 416mm (Data Balai Besar Meteorologi Klimatologi dan Geofisika Wilayah III Denpasar tahun 20082017). Arah angin dominan dari arah Tenggara pada bulan April-November dan Barat Daya pada bulan Januari, Februari dan Desember. Wilayah perencanaan termasuk tipe iklim C2 berdasarkan klasifikasi SchmidtFerguson yang berarti memiliki tipe iklim agak basah dengan vegetasi hutan rimba, yang terdiri dari 5-6 bulan basah dan 2-3 bulan kering (Bappeda, Kabupaten Gianyar tahun 2018). Sumber air tapak berasal dari PDAM dan hasil intalasi Waste water Garden (WWG). Drainase berupa drainase terbuka dan tertutup buatan. Vegetasi yang ada pada tapak yaitu Sukun (Artocarpus altillis), Nangka (Artocarpus heterophyllus), Pepaya (Carica papaya L.), Talas (Colocasia esculenta L.), Lempuyang (Zingiber zerumbet), Rumput paetan (Axonopus compresus) dan Pakis (Pteridium aquilinum ssp. Latiusculum). Satwa yang ada pada tapak merupakan satwa liar pada umumnya yang sering dijumpai di lingkungan sekitar baik di kawasan perkotaan maupun habitat alami yaitu capung (Pantala flavescens), belalang (Dissosteira carolina), kadal kebun (Eutropis multifasciata), dan burung gereja (Passer montanus).

\subsection{Analisis dan Sintesis}

Lokasi tapak dapat dibilang cukup strategis karena dekat dengan Kecamatan Ubud yang memiliki destinasi wisata yang banyak diminati wisatawan. Letak tapak penelitian berada diantara vila dan di tepi jalan raya, sehingga tapak penelitian cukup mudah ditemukan pengunjung. Ditinjau dari kemiringan lahan, tapak penelitian memiliki kemiringan lahan bervariasi antara 5,4\%-50\%. Berdasarkan klasifikasi kemiringan lahan menurut Surat Menteri Pertanian No.:837/KPTS/UM/11/1980, kondisi ini termasuk dalam kategori landaicuram. Berdasarkan aspek iklim mikro, suhu pada tapak penelitian termasuk dalam kategori hangat nyaman dan curah hujan pada tapak yang cukup tinggi pada musim pengjujan. Vegetasi dan satwa pada tapak kaya akan tanaman buah lokal yang cukup banyak sehingga dapat dimanfaatkan untuk membudidayakan komoditas tanaman yang bermanfaat untuk keperluan vila maupun warga sekitar. Analisis vegetasi dilakukan melalui pengukuran terhadap habitus atau perawakan tanaman (Heddy, 1997). Analisisi vegetasi yang telah dilakukan diperoleh informasi kuantitatif komunitas tumbuhan dalam tapak penelitian pada Tabel 1.

Tabel 1.Analisis vegetasi Villa Cloud Nine Estate

\begin{tabular}{|c|c|c|c|}
\hline \multirow{2}{*}{ No. } & \multicolumn{2}{|r|}{ Nama Tanaman } & \multirow{2}{*}{$\operatorname{INP}(\%)$} \\
\hline & Nama lokal & Nama Latin & \\
\hline & Pohon & & \\
\hline 1. & Sukun & Artocarpus altillis & 9,395 \\
\hline 2. & Nangka & Artocarpus heterophy & 68,245 \\
\hline 3. & Pepaya & Carica papaya L. & 22,053 \\
\hline 4. & Palem ekor ikan & Caryota mitis & 23,966 \\
\hline 5. & Kelapa & Cocos nucifera & 35,7043 \\
\hline 6. & Mangga & Mangifera indica & 49,820 \\
\hline 7. & Singkong & Manihot esculenta & 38,719 \\
\hline \multirow[t]{3}{*}{8.} & Pisang & Musa sp. & 52,094 \\
\hline & Total INP (\%) & & 300,000 \\
\hline & Semak & & \\
\hline 1. & Alokasia & Alocasia macrorrhiza & 95,647 \\
\hline 2. & Talas & Colocasia esculenta $L$. & 51,739 \\
\hline 3. & Suji & Dracaena angustifolia & 35,037 \\
\hline 4. & Salak & Salaca zalacca & 48,503 \\
\hline \multirow[t]{2}{*}{5.} & Lempuyang & Zingiber zerumbet & 69,072 \\
\hline & Total INP (\%) & & 300,000 \\
\hline
\end{tabular}




\begin{tabular}{lllc}
\hline \multirow{2}{*}{ No. } & \multicolumn{1}{c}{ Nama lokal } & \multicolumn{1}{c}{ Nama Latin } & \multirow{2}{*}{ INP (\%) } \\
\cline { 2 - 3 } & Ground cover & & \\
1. & Rumput paetan & Axonopus compresus & 105.407 \\
2. & Pakis & Pteridium aquilinum ssp. latiusculum & 94,592 \\
\hline & Total INP (\%) & & 200,000 \\
\hline
\end{tabular}

Berdasarkan data inventarisasi data dan analisis yang ada maka dapat dijelaskan sintesis pada tapak sebagai berikut. Villa Cloud Nine Estate dapat dibuat area permakultur karena lokasinya yang cukup strategis dan memiliki keberagaman kemiringan lahan. Dengan keberagaman kemiringan lahan tersebut merupakan potensi agar dapat menonjolkan good view dan memaksimalkan penggunaan lahan yang sesuai dengan kebutuhan permakultur.

Kondisi kemiringan lahan yang cenderung cukup curam di beberapa area pada tapak dapat mengakibatkan erosi, hal ini dapat dilakukan melalui pembuatan bio retaining wall secara biologis maupun secara mekanik, disesuaikan dengan tingkat kemiritngan lahan. Solusi lain pengurangan laju erosi pada tapak di area curam dapat digunakan sebagai media tanamn dan konservasi dengan cara pembuatan terasering, penanaman sejajar kontur, dan penanaman penutup tanah. Menurut Ariyanto (2012), jenis tanah regosol dapat digunakan untuk lahan sawah, palawija, sayur- sayuran, perkebunan (tembakau dan tebu) dan lainnya. Tanah regosol memiliki produktivitas tanah sedang sampai tinggi, akan tetapi dengan pemupukan secara berkala, pemberian bahan organik dan pengairan akan meningkatkan unsur hara pada tanah.

Berdasarkan hasil analisis aspek iklim mikro pada tapak, kelembaban udara di tapak tergolong cukup tinggi pada musim penghujan sehingga hal ini dapat berdampak tidak baik bagi tanaman maupun manusia. Kelembaban tersebut dapat dikurangi dengan cara pemilihan pola struktur vegetasi yang tepat sehingga sinar matahari dapat masuk ke dalam tapak. Intensitas penyinaran juga mempengaruhi tanaman, ada tanaman yang membutuhkan intensitas matahari penuh, sedang maupun rendah. Intensitas matahari juga mempengaruhi pembuhanan dan pembungaan pada tanaman, maka dari itu diperlukannya penempatan lokasi yang sesuai agar tanaman dapat tumbuh optimal.

\subsection{Diagram Konsep}

\subsubsection{Konsep dasar}

Konsep dasar desain tapak pada penelitian ini adalah mengangkat konsep The Journey of Permaculture, yakni sebuah konsep permakultur yang menyeleraskan aspek peduli terhadap bumi, peduli terhadap manusia dan peduli terhadap masa depan. Konep ini didasarkan dari etika dan prinsip permakultur yang dapat diaplukasikan dengen menciptkan lingkungan hijau, meminimalkan pembuangan dan mengunakan material yang ramah lingkungan serta mudah didapatkan.

\subsubsection{Konsep pengembangan}

\subsubsection{Konsep ruang dan aktivitas}

Konsep ruang dikembangkan berdasarkan pada analisis dan sintesis yang telah dilakukan pada beberapa aspek lanskap yang sudah di inventarisasi. Ruang dikelompokan menurut fungsinya sehingga dapat terbentuk zona 1, zona 2, dan zona 3. Menurut IDEP (2016), menciptakan zona dapat membantu menghemat waktu dan tenaga yang diperkukan untuk menciptakan sebuah sistem permakultur. Zona 1 pada tapak penelitian yaitu zona yang paling sering dikunjungi dan memiliki intensitas tinggi dalam pemeliharaannya seperti area penerimaan, rumah atau vila, penampungan air, kolam penampungan limbah, dan area tanaman produksi sayur atau community garden. Zona 2 yaitu zona yang cukup sering dikunjungi oleh pengunjung maupun pengelola dan pemeliharan pada zona 2 cenderung cukup rendah pemeliharannya. Zona 3 yaitu zona yang jarang dikunjungi dan pemeliharaannya cenderung ekstensif seperti area hutan masyarakat.

\subsubsection{Konsep sirkulasi}

Konsep sirkulasi yang di terapkan dalam tapak terdiri atas dua sirkulasi yaitu sirkulasi primer dan sirkulasi sekunder. Sirkulasi primer yaitu jalur yang ditujukan untuk pejalan kaki baik pengunjng maupun pengelola. Sirkulasi sekunder yaitu jalur yang dapat mengakomodasi pengunjung maupun pengelola agar lebih menjelajah ke dalam perkebunan. 


\subsubsection{Konsep vegetasi}

Konsep vegetasi tapak berkaitan erat dengan pengembangan permakultur. Konsep vegetasi mengutamakan penggunaan tanaman eksisting dan tanaman introduksi sesuai dengan tujuan perencanaan, fungsi tanaman dan zona yang dikembangkan. Konsep vegetasi berdasarkan fungsi tanaman terdiri dari tanaman produksi, tanaman konservasi, dan tanaman penunjang.

\subsubsection{Konsep hidrologi}

Konsep hidrologi dan drainase pada tapak memiliki peran penting dalam memengaruhi kondisi iklim mikro pada tapak. Konsep hidrologi dan drainase ini dilakukan dalam upaya menicptakan manajemen air yang berkelanjutan, hal ini dilakukan dengan menciptakan sistem yang menyerupai di alam. Konsep hidrologi dan tapak penelitian terdiri dari wastewater garden, stormwater management, dan waterfeature.

3.4.2.5 Rencana Blok (Block plan)

Rencana blok (Gambar 2) merupakan penggabungan dari berbagai aspek pada konsep pengembangan tapak secara spasial dengan menerapkan konsep desain sehingga menghasilkan gambaran rencana tapak yang cukup detail.

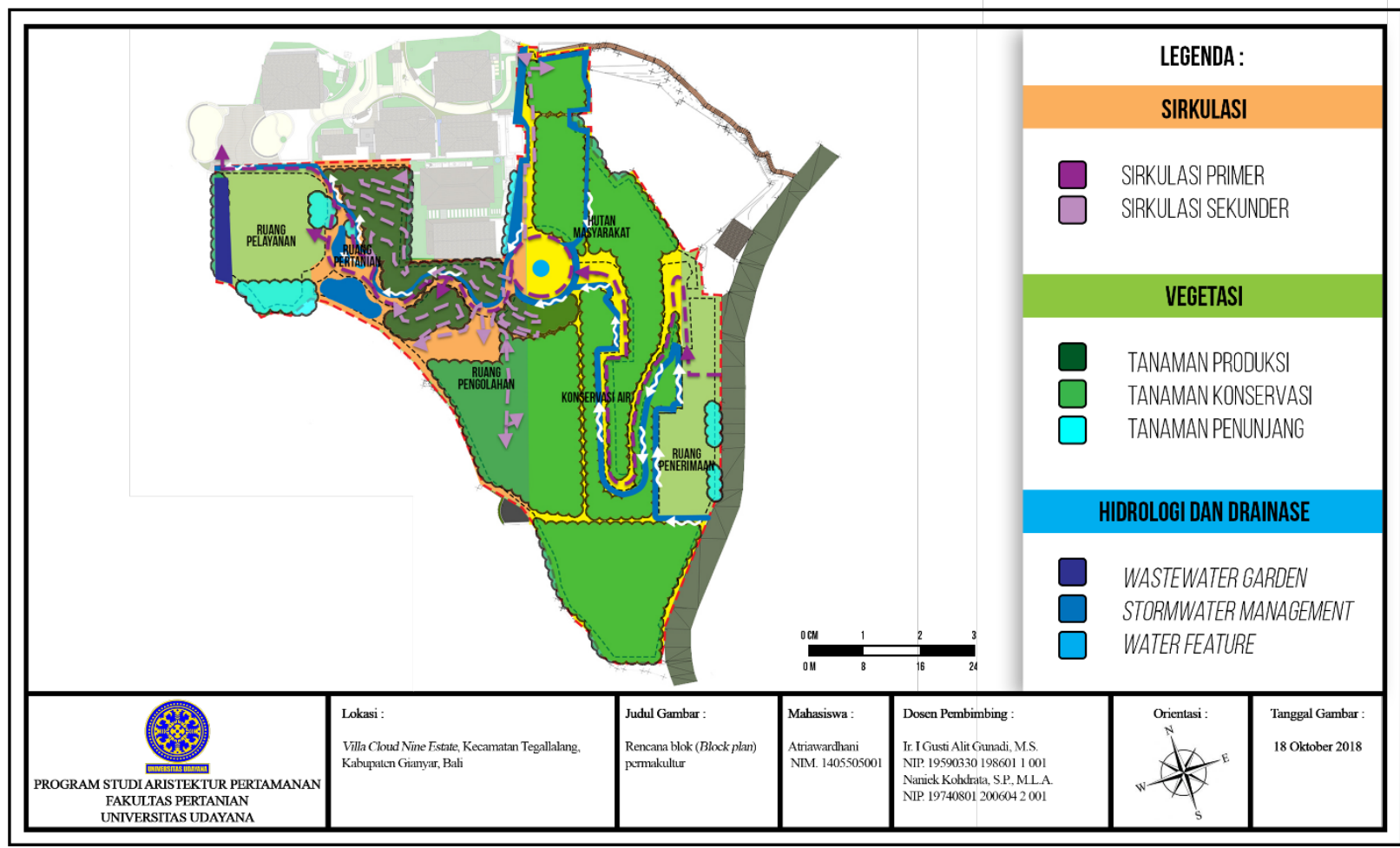

Gambar 2. Rencana blok permakultur di Villa Cloud Nine Estate

\subsection{Perencanaan Lanskap}

\subsubsection{Rencana tata ruang}

Rencana tata ruang area permakultur di Villa Cloud Nine Estate merupakan pengembangan dari konsep tata ruang yang terbagi dalam tiga zona. Pada tabel 2 merupakan rencana ruang, aktivitas, dan fasilitas pada tapak penelitian.

Tabel 2. Rencana ruang, aktivitas, dan fasilitas tapak penelitian

\begin{tabular}{clll}
\hline Zona & \multicolumn{1}{c}{ Area } & \multicolumn{1}{c}{ Aktivitas/ Fungsi } & \multicolumn{1}{c}{ Fasilitas } \\
\hline Zona 1 & Area penerimaan & Area pertemuan, keluar masuk & Restaurant, \\
& (Welcome Area) & tapak, memarkir kendaraan & Tempat parkir, \\
& & & Signage \\
\hline
\end{tabular}




\begin{tabular}{|c|c|c|c|}
\hline Zona & Area & Aktivitas/ Fungsi & Fasilitas \\
\hline & Area pelayanan & $\begin{array}{l}\text { Memperoleh informasi, memesan } \\
\text { vila }\end{array}$ & $\begin{array}{l}\text { Resepsionis, toilet, water } \\
\text { feature, spa, vila }\end{array}$ \\
\hline \multirow[t]{2}{*}{ Zona 2} & $\begin{array}{l}\text { Area pertanian sayuran } \\
\text { (Community Garden) }\end{array}$ & $\begin{array}{l}\text { Bertani, mengumpulkan hasil } \\
\text { panen, pelatihan pertanian, } \\
\text { keliling kebun }\end{array}$ & Tanaman sayuran, signage \\
\hline & Area pengolahan & $\begin{array}{l}\text { Pengenalan satwa, pemberian } \\
\text { makan bebek, pengenalan } \\
\text { pengolahan pupuk kandang, } \\
\text { pengenalan pengolahan benih }\end{array}$ & $\begin{array}{l}\text { Green house, kandang } \\
\text { bebek, bioretention basins }\end{array}$ \\
\hline \multirow[t]{2}{*}{ Zona 3} & Area konservasi air & $\begin{array}{l}\text { Area penampungan dan } \\
\text { penjernihan air }\end{array}$ & $\begin{array}{l}\text { Drainase, bioretention } \\
\text { swales, waste water garden, } \\
\text { rain garden }\end{array}$ \\
\hline & Hutan masyarakat & Area konservasi lahan & Tanaman konservasi \\
\hline
\end{tabular}

Pada zona satu terdapat area penerimaan merupakan identitas pertama yang dijumpai pengunjung. Fungsi ruang penerimaan adalah untuk menonjolkan citra vila. Area ini memiliki fasilitas tempat parkir, signage, dan restaurant. Kemudian pada zona satu terdapat area pelayanan, yaitu area yang memiliki fokus untuk memfasilitasi pengunjung agar mendapatkan pelayanan di vila. Area pelayanan ini berupa gedung resepsionis sebagai media untuk mempermudah pengunjung dalam menyewa vila dan mendapatkan informasi lengkap mengenai permakultur yang ada pada vila.

Pada zona dua terdapat dua area yaitu area pertanian sayuran dan area pengolahan. Area pertanian sayuran yang terletak pada area dekat vila. Hal ini agar memudahkan akses pengunjung maupun pengelola vila untuk melakukan kegiatan berkebun. Area pengolahan merupakan salah satu atraksi yang ada pada tapak penelitian. Pada area pengolahan terdapat fasilitas green house dan kandang bebek. Fasilitas kandang bebek bertujuan agar pengunjung mendapatkan pengalaman dan pelajaran menyeluruh tentang pertanian termasuk peternakan didalamnya.

Zona yang selanjutnya yaitu zona tiga yang terdiri dari area konservasi air dan hutan masyarakat. Area konservasi air merupakan area yang penggunaan fasilitasnya diterapkan secara bersamaan dengan fasilitas pada area pertanian sayur dan peternakan. Kemudian hutan masyarakat merupakan salah satu langkah untuk mengembalikan keseimbangan alam. Penanaman pohon ini dapat membantu menghentikan erosi, memperbaiki kerusakan lahan sekaligus memberikan pangan, kayu, dan obat-obatan. Perspektif setiap area dapat dilihat pada Gambar 3.

\subsubsection{Rencana sirkulasi}

Sirkulasi merupakan penghubung antara ruang satu dengan yang lainnya. Rencana sirkulasi dan aksesibilitas tapak disesuaikan dengan area permakultur. Rencana sirkulasi ini mengikuti konsep pengembangannya yaitu jalur sirkulasi primer dan jalur sirkulasi sekunder. Sirkulasi primer merupakan jenis sirkulasi yang didesain agar memmudahkan pengunjung maupun pengelola dalam beraktivitas. Sirkulasi ini digunakan sebagai penghubung antar ruang pada tapak. Sirkulasi ini memiliki lebar 1,5 $m-2,5 \mathrm{~m}$ sehingga memiliki kapasitas yang cukup dalam menerima pengunjung yang masif. Material yang digunakan merupakan material bertekstur halus hingga tekstur sedang dengan permukaan rata sehingga dapat dilalui mudah oleh pengunjung.

Sirkulasi sekunder digunakan sebagai jalur interpretasi tambahan pada area pertanian sayur dan kebun buah. Jalur ini dapat mengakomodasi pengunjung dan pengelola agar lebih menjelajah ke area pertanian sayur dan perkebunan sawah. Sirkulasi ini memiliki lebar $0,3 \mathrm{~m}-1,0 \mathrm{~m}$ sehingga hanya dapat dilalui oleh satu orang. Penggunaan material pada sirkulasi sekunder menggunakan material halus hingga kasar dengan permukaan rata hingga bergelombang serta menggunakan rumput, hal ini bertujuan untuk memberikan pengalaman berbeda bagi pengunjung tapak 

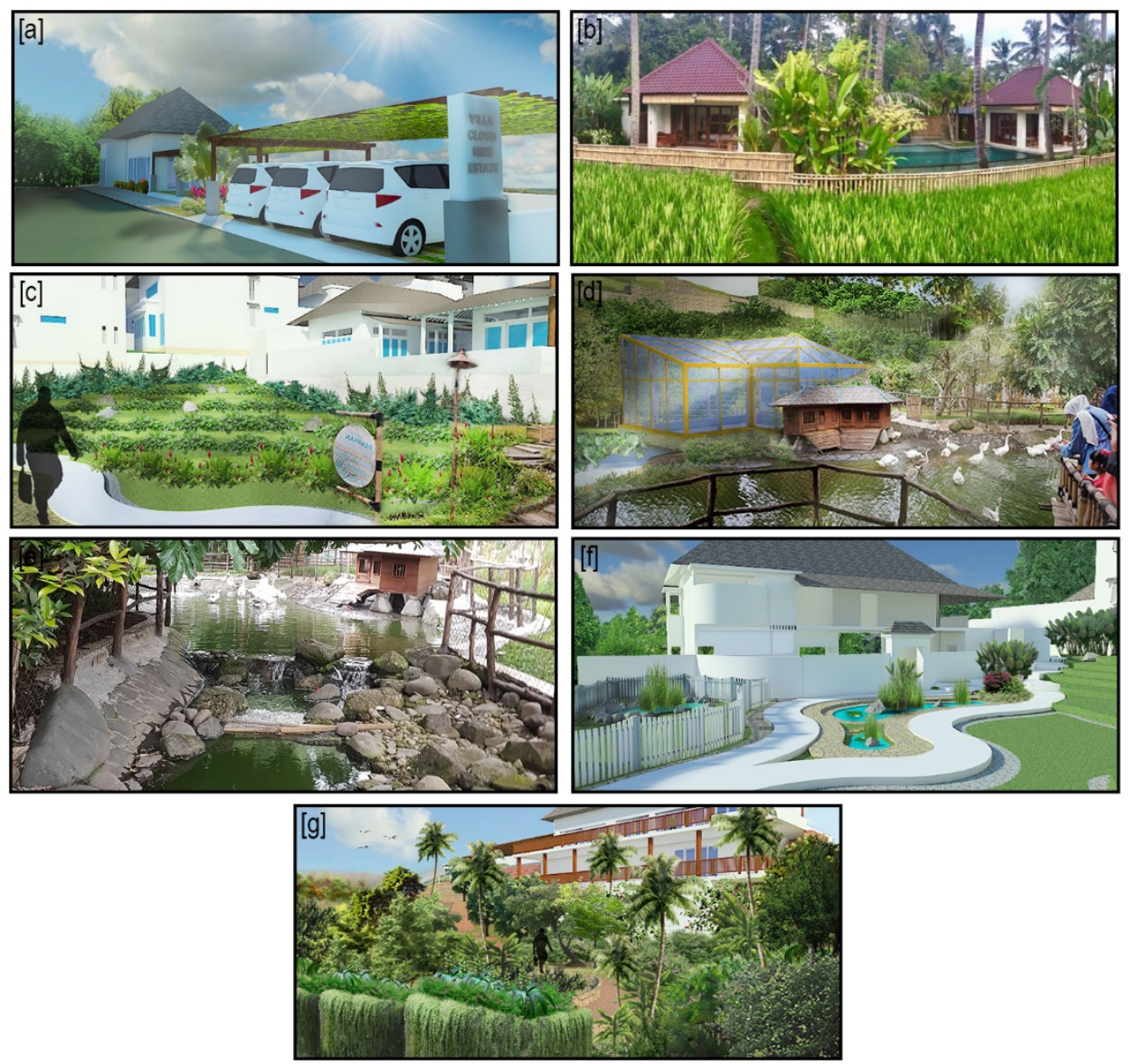

Gambar 3. Perspektif area pada Villa Cloud Nine Estate

[a] Area penerimaan, [b] Area pelayanan, [c] Area pertanian sayur (Community garden), [d] Area pengolahan, [e] Ilustrasi area konservasi air, [f] Area konservasi air, [g] Hutan masyarakat

\subsubsection{Rencana vegetasi}

Rencana tata vegetasi pada tapak dikembangkan dari konsep vegetasi permakultur yang menonjolkan tanaman produksi, maka dari itu pemilihan tanamannya tidak terlepas dari fungsi dan estetikanya saja tapi juga dapat mendukung konsep permakultur. Rencana tata vegetasi berdasarkan konsep yang telah disusun sebelumnya membagi tata vegetasi menjadi tiga fungsi yaitu tanaman produksi, tanaman konservasi dan tanaman penunjang.

Vegetasi utama merupakan tanaman produksi yang difungsikan untuk kepentingan pendidikan dan keperluan sehari- hari bagi pengunjung maupun pengelola. Vegetasi pada tapak dikelompokan berdasarkan kedekatan kepekaan vegetasi. Pengelompokan kedekatan berdasarkan analisis kepekaan vegetasi dimaksudkan untuk menentukan pola penanaman yang tepat sehingga kelestarian tanaman tetap terjaga.

Tanaman produksi buah eksisting pada tapak pada mulanya berjumlah tujuh jenis, untuk menunjang konsep permakultur maka ditambahkan tanaman buah dengan jumlah 10 jenis. Tanaman buah yang memiliki tingkat kepekaan vegetasi sedang diletakan di dekat area parkir dan restaurant, hal ini dimaksudkan agar pengelolaan dan pemeliharaan tanaman dapat dilakukan dengan mudah.

Tanaman produksi sayur berjumlah 15 jenis, pemilihan jenis tanaman ini disesuaikan dengan kondisi iklim dan topografi pada tapak. Tanaman kacang (Arachis hypogaea) diletakan di area pertanian sayur, karena pada area ini memiliki topografi yang bervariasi sehingga tanaman kacang dapat menahan lajur tanah pada area tersebut agar tidak terjadi erosi. Tanaman kacang juga dapat berfungsi sebagai pagar hidup sebagai penahan angin untuk bedeng tanaman sayuran (IDEP, 2016). Tanaman labu siam (Sechium edule) dan kacang panjang (Vigna unguiculata ssp. Sesquipedalis) diletakan di sisi dinding area pertanian sayur untuk memaksimalkan penggunaan lahan pada tapak. Tanaman produksi sayur tidak semuanya ditanam secara 
bersamaan akan tetapi tanaman ini ditanam secara bergiliran berdasarkan rotasi tanaman dengan keperluan dan kebutuhan vila agar memberikan variasi bagi hasil tanaman produksi sayur. Sangat baik untuk melakukan rotasi tanaman dari bedeng ke bedeng tiap musimnya, atau lebih baik untuk menanam berbagai jenis tanaman secara bersamaan. Rotasi tanaman akan membantu mengurangi masalah hama dan penyakit tanaman.

Pemilihan tanaman konservasi pada tapak terbagi menjadi dua yaitu tanaman untuk konservasi air dan konservasi tanah. Tanaman untuk konservasi air dipilih yang dapat menyaring air seperti tanaman teratai (Nymphaea lotus) yang akan diletakan pada area konservasi air. Sedangkan tanaman untuk konservasi tanah yaitu tanaman pakis (Nephrolepis exaltata) diletakan pada area yang memiliki topografi terjal seperti pada area kebun buah dan hutan masyarakat. Pemilihan tanaman penunjang berdasarkan tanaman eksisting yang ada pada Villa Cloud Nine Estate. Rencana tata vegetasi dapat pada Gambar 4.

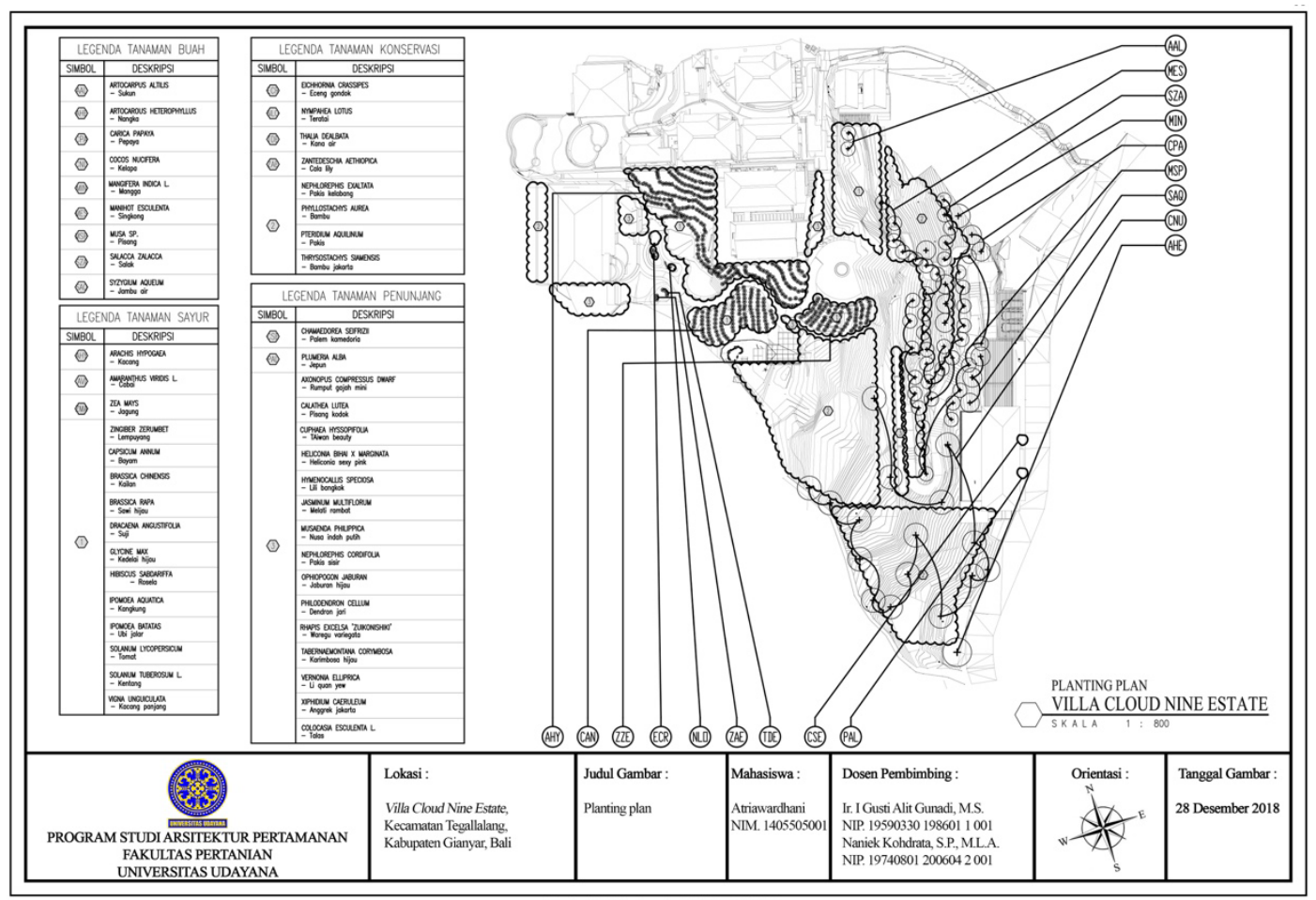

Gambar 4. Planting plan Villa Cloud Nine Estate

\subsubsection{Rencana hidrologi}

Rencana tata hidrologi pada tapak dikembangkan dari konsep hidrologi dan drainase, hal ini dikarenakan agar terciptanya manajeman air yang berkelanjutan pada tapak. Dalam rencana hidrologi pada tapak akan menerapkan stormwater management yaitu konsep manajemen air yang memerhatikan air hujan sebagai bagian penting dalam sistem tersebut. Stormwater management memiliki manfaat sebagai membantu proses penjernihan air secara alami, menjaga kelestarian ekosistem alam dan mengatur iklim mikro pada tapak. Secara teknis, stormwater management memanfaatkan air hujan sebagai sumber air pada kolam. Stormwater management yang diterapkan pada tapak penelitian meliputi saluran drainase yang mengubungkan dengan bioretention swales, serta kolam berbentuk bioretention basins.

Selanjutnya rencana hidrologi dan drainase yang akan diterapkan adalah Waste water Garden (WWG). Sistem WWG cukup banyak diterapkan di hotel dan resort di Bali, hal ini karena WWG merupakan salah satu solusi pengolahan air limbah rumah tangga yang hemat dan praktis dengan biaya pemeliharaan yang rendah dan aman (IDEP, 2016). Air hasil pengolahan waste water garden dapat digunakan untuk irigasi sayur- sayuran, semak, pepohonan, atau disebarkan melalui aliran irigasi untuk menyiram kebun, dan dapat pula digunakan untuk membersihkan toilet kembali.

Water feature pada rencana hidrologi dan drainase tapak merupakan area yang memiliki fungsi utama untuk meningkatkan nilai estetika pada tapak. Berebeda dari stormwater management yang memiliki 
kesan alami, water feature cenderung memiliki kesan buatan. Walau demikian pada beberapa area stormwater management juga ditempatkan water feature yang memiliki kesan alami (natural). Secara teknis, water feature yang akan diterapkan pada tapak terdiri atas kolam dan air mancur.

\subsubsection{Rencana Induk}

Rencana induk lanskap merupakan pengembangan lebih lanjut dari rencana blok dengan memerhatikan detail elemen lanskap dan proporsi skala pada desain lanskap. Secara spasial gambar rencana induk masterplan dapat dilihat pada Gambar 5.

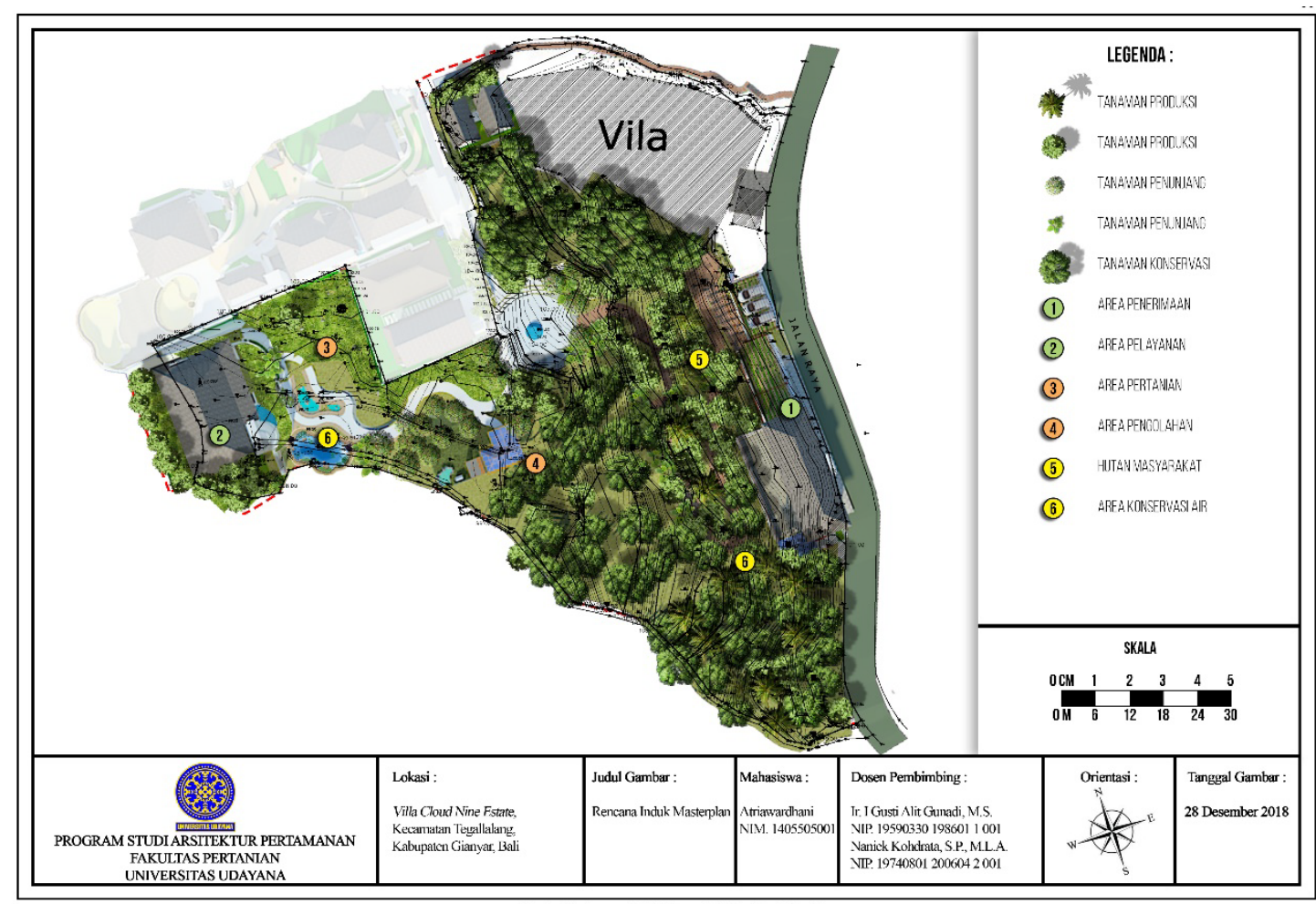

Gambar 5. Rencana Induk Villa Cloud Nine Estate

\section{Simpulan dan Saran}

\subsection{Simpulan}

Berdasarkan penelitian, tapak memiliki karakteristik dataran rendah dengan curah hujan cukup tinggi sepanjang tahun. Karakter lanskap pada tapak yaitu alami dengan elemen lanskap utama berupa hamparan rumput dan pepohonan. Konsep dasar rencana permakultur pada Villa Cloud Nine Estate yaitu The Journey of Permaculture diterapkan melalui prinsip dan etika permakultur yaitu peduli terhadap lingkungan, peduli terhadap manusia dan peduli terhadap bumi. Tujuan dari konsep tersebut untuk memberikan pengalaman bagi pengunjung terhadap area permakultur itu sendiri melalui pembelajaran mengenai bercocok tanam dan beternak. Konsep dasar yang dirumuskan kemudian dikembangkan kembali dengan konsep ruang dan aktivitas, konsep sirkulasi, konsep vegetasi, dan konsep hidrologi.

Pada area permakultur terbagi menjadi tiga zona. Zona ini diklasifikasikan berdasarkan prinsip dan etika permakultur dimana zona satu merupakan zona yang memiliki intensitas sering dikunjungi dan membutuhkan perawatan yang intensif dan zona yang paling luar atau zona tiga merupakan zona yang memiliki intensitas jarang dikunjungi dan perawatan yang ekstensif. Vegetasi pada area permakultur terbagi menjadi tiga yaitu tanaman produksi, tanaman konservasi, dan tanaman penunjang. Pada area permakultur tanaman produksi menjadi tanaman utama.

\subsection{Saran}

Penelitian ini menghasilkan alternatif rencana permakultur yang dapat digunakan sebagai acuan pemikiran dan pertimbangan dalam pengembangan kawasan permakultur pada Villa Cloud Nine Estate 
ataupun di kawasan lain yang memiliki karakteristik lanskap dataran rendah dan topografi yang bervariasi. Penelitain ini juga bersifat studi kasus, sehingga perlu dianalisis kembali penerapannya pada lokasi lain.

\section{Daftar Pustaka}

Ariyanto, Dwi Priyo. IImu Tanah. Universitas Sebelas Maret Surakarta. Solo. Tidak dipublikasikan.

Balai Besar Meteorologi Klimatologi dan Geofisika Wilayah III Denpasar. 2018. Data Unsur Iklim Bulanan. Pelayanan Jasa Informasi Klimatologi.

Bappeda. 2018. Rencana Detail Tata Ruang Kecamatan Tegallalang. Badan Perencanaan Pembangunan Daerah Kabupaten Gianyar.

Eri, I Wayan. 2017. Miris, Kepala Subak Malah Jadi Makelar Tanah, Alih Fungsi Lahan Ubud Makin Tinggi. Tersedia online di : http://bali.tribunnews.com/2017/02/17/miris-kepala-subak-malah-jadi-makelartanah-alih-fungsi-lahan-di-ubud-makin-tinggi (Diakses pada tanggal 28 Januari 2018).

Gold S.M. 1980. Recreation Planning and Design. Mc Graw Hill, New York.

Heddy, Suwasono. 1997. Metode Analisis Vegetasi dan Komunitas. Penerbit Institut Pertanian Bogor, Bogor. IDEP. 2016. A Resource Book for Permaculture: Solutions for Sustainable Lifestyle. IDEP Foundation, Denpasar.

Kusniarti, Seri AA.2017. Jumlah Hotel di Bali Naik Jadi 2.079, Disparda dan PHRI Usulkan Moraturium. Tersedia online di : http://bali.tribunnews.com/2017/04/20/jumlah-hotel-di-bali-naik-jadi2079disparda-dan-phri-usulkan-moratotium?page=all (diakses pada tanggal 23 Desember 2017).

Menteri Pertanian. 1980. Surat Keputusan Menteri Pertanian Nomor 837/KPTS/UM/11/1980 Tentang Kriteria dan Tata Cara Penetapan Hutan Lindung. Menteri Pertaninan. Jakarta.

Suastika, I Ketut. 2017. Devisa Bali Meningkat 8,12 Persen. Tersedia online di : http://bali.antaranews.com/berita/103353/devisa-bali-meningkat-812-persent (diakses pada tanggal 20 Desember 2017). 